\title{
Identifikasi dan Pengukuran Ketercapaian Implementasi Knowledge Transfer pada Direktorat Human Resource Development PT. Pelindo III (Persero)
}

\author{
Abyan Naufal Allam dan Bambang Syairudin \\ Departemen Teknik Industri, Fakultas Teknologi Industri, Institut Teknologi Sepuluh Nopember (ITS) \\ e-mail: bambangsy@ie.its.ac.id
}

\begin{abstract}
Abstrak-PT Pelabuhan Indonesia III (Persero) merupakan salah satu perusahaan BUMN terbesar yang bergerak dibidang operator pelabuhan. Dengan dikeluarkanya peraturan pemerintah nomor 17 tahun 2008, memberikan ancaman tersendiri bagi PT Pelindo III akan munculnya pesaing-pesaing usaha sejenis. Melihat bahwa sebelumnya PT Pelindo III merupakan perusahaan pelabuhan satu-satunya di Indonesia yang memiliki knowledge penting, membuat PT Pelindo III menginisiasikan untuk melakukan perancangan knowledge management pada perusahaan tekhusus pada direktorat human resource development. Namun dalam berjalannya knowledge management tersebut masih sering terjadi kesalahan-kesalahan kerja pada pegawai. sehingga diperlukan suatu pengukuran terhadap knowledge transfer yang menjadi pilah pada knowledge management itu sendiri. Dalam penelitian ini akan dirancang sebuah pengukuran ketercapaian implementasi knowledge transfer pada direktorat human resource development di PT Pelindo III (Persero). Proses pengidentifikasian knowledge akan dilakukan dengan menggunakan knowledge audit, kemudian dilakukan pembobotan dan pengukuran aspek knowledge transfer dengan menggunakan framework SECI, dan dilakukan pengolahan data menggunakan river diagram serta stairs diagram. Bedasarkan hasil identifikasi terdapat total 79 knowledge yang terdiri dari empat divisi pada direktorat human resource development. Dan didapatkan adanya gap ketercapaian implementasi knowledge transfer pada tiap knowledge yang ada.
\end{abstract}

Kata Kunci-Knowledge, Knowledge Transfer, Knowledge Management, River Diagram, Stairs Diagram.

\section{PENDAHULUAN}

$\mathrm{P}$ T Pelabuhan Indonesia III sangat memegang peranan yang penting dalam kemajuan kemaritiman di Indonesia. Hal ini dikarenakan saat ini, PT Pelindo III, sebagai operator terminal pelabuhan mengelola 43 pelabuhan dengan 16 kantor cabang yang tersebar di tujuh provinsi di Indonesia meliputi Jawa Tengah, Jawa Timur, Bali, Nusa Tenggara Barat, Nusa Tenggara Timur, Kalimantan Tengah, dan Kalimantan Selatan [1]. Sebagai perusahaan yang bergerak dibidang operator bisnis pelayaran, PT Pelabuhan Indonesia III bertanggung jawab sebagai support operator bagi pelabuhan-pelabuhan yang ada. Hal tersebut berdampak pada peningkatan knowledge yang dimiliki oleh para pekerja yang selanjutnya akan menjadi seorang ahli di perusahaan tersebut. Knowledge tersebut sangatlah penting bagi PT Pelabuhan Indonesia III karena pengetahuan mengenai pelabuhan di Indonesia sangat jarang dan terbilang langka di Indonesia. Sadnyana memaparkan bahwa PT Pelabuhan Indonesia III memiliki banyak ahli senior dalam bidangnya masing-masing [2]. Namun, hal ini tidak selaras dengan proses transfer knowledge yang seharusnya ada pada perusahaan karena proses penerimaan karyawan ataupun pekerja tidak terjadwal secara periodik. Dalam sepuluh tahun terakhir PT Pelabuhan Indonesia III melakukan penerimaan karyawan sebanyak satu kali yaitu pada tahun 2011. Sebelum penerimaan karyawan tersebut, terakhir kali PT. Pelabuhan Indonesia III mengadakan penerimaan karyawan pada tahun 1998/1999. Berdasarkan pemaparan tersebut jarak penerimaan karyawan baru ini berdampak pada risiko hilangnya knowledge yang ada karena terdapat kesenjangan waktu yang cukup jauh antar penerimaan karyawan. Sehingga tedapat risiko-risiko kehilangan knowledge yang dapat terjadi seperti pekerja yang dalam periode tersebut pensiun, pekerja yang mundur dari jabatannya dan kegiatan mutasi yang terjadi di perusahaan. Dilain sisi pada tahun 2008 pemerintah mengeluarkan Undang Undang nomor 17 mengenai pelayaran. Undang - undang tersebut merupakan pengaturan untuk bidang kepelabuhan yang memuat ketentuan mengenai penghapusan monopoli dalam penyelenggaraan pelabuhan, pemisahan antara fungsi regulator, dan operator serta memberikan peran serta pemerintah daerah dan swasta secara proposional di dalam penyelenggaraan kepelabuhan. Dengan adanya peraturan tersebut berimplikasi pada adanya ancaman tersendiri bagi PT Pelabuhan Indonesia III yang diakibatkan karena akan adanya perusahaan swasta maupun daerah sebagai pesaing.

Melihat permasalahan-permahasalahan tersebut tentunya PT Pelabuhan Indonesia III Surabaya melakukan langkah-langkah pencegahan ancaman dengan melakukan perbaikan-perbaikan pada segala aspek proses bisnis yang ada. Salah satu bagian yang menjadi konsentrasi utama dalam perbaikan berjalannya proses bisnis adalah pengembangan sumber daya manusia. Bagi perusahaan besar seperti PT Pelabuhan Indonesia III, pengelolaan sumber daya manusia sangat penting, hal ini dikarenakan pengelolaan sumber daya manusia dapat mempengaruhi aspek-aspek atau bagian lainnya didalam 
perusahaan. Salah satu aspek yang dikembangkan pada bagian sumber daya manusia adalah pengelolaan knowledge yang sangat penting dalam menghadapi permasalahan-permasalahan yang terjadi.

Knowledge atau pengetahuan sangatlah penting sebagai sumber daya strategis dan merupakan penentu penting dari keunggulan kompetitif perusahaan [3]. Selain itu knowledge sangatlah penting bagi sebuah instansi, organisasi atau perusahaan karna merupakan aset intangible yang memiliki nilai tinggi. Dilain sisi bagi perusahaan pelabuhan seperti PT. Pelabuhan Indonesia III, knowledge akan proses bisnis pelabuhan sangat berharga karena merupakan pengetahuan yang jarang diketahui karena PT Pelabuhan Indonesia III merupakan perusahaan pelabuhan terbesar di Indonesia. Berkenaan dengan hal tersebut, PT Pelabuhan Indonesia III mulai mengimplementasikan knowledge management pada perusahaan sebagai langkah strategis menanggapi permasalahan-permasalahan yang ada. Dalam pengimplementasiannya salah satu aspek yang berjalan pada knowledge management process tentunya adalah knowledge transfer. Namun dalam pengimplementasian knowledge transfer tersebut tentunya perlu diketahui bagaimana berjalannya knowledge transfer tersebut agar tetap mengacu pada tujuan dan strategi perusahaan. Sebab, Sadnyana memaparkan, walaupun knowledge management tersebut telah dilakukan, masih terdapat kesalahan-kesalahan yang dilakukan berulang oleh pegawai terutama pada bagian human resource development. Hal ini selaras dengan pernyataan Awad dan Ghaziri mengenai knowledge transfer merupakan langkah untuk mengetahui hal-hal yang yang seharusnya dilakukan pekerja dan juga hal kritis untuk meningkatkan performansi serta menghilangkan gap yang ada pada karyawan antara apa yang mereka lakukan dengan apa yang mereka mengerti dalam pekerjaannya [4].

Oleh sebab itu, pengukuran merupakan hal yang sangat penting. Kaplan dan Norton mengatakan bahwa "jika anda tidak dapat mengukurnya, Anda tidak dapat mengelolanya"[5]. Oleh sebab itu pengukuran terhadap berjalannya knowledge management terkhusus pada knowledge transfer yang berjalan pada suatu perusahan sangat diperlukan agar knowledge management process berjalan secara efektif. Hal ini diperkuat dengan belum adanya pengukuran terhadap ketercapaian implementasi knowledge transfer pada PT Pelabuhan Indonesia III. Menurut American Productivity \& Quality Center (APQC) untuk mengoptimalkan daya guna dari knowledge di suatu organisasi tertentu, perlu adanya suatu pengukuran [6]. Oleh karena itu, penelitian ini ingin menitikberatkan pada pengukuran terhadap ketercapaian implementasi knowledge transfer pada bagian human resource development PT Pelabuhan Indonesia III (Persero).

\section{METODOLOGI PENELITIAN}

\section{A. Identifikasi dan Perumusan Masalah}

Pada tahap perumusan masalah ini akan dijalani beberapa proses yang mendukung untuk dapat merumuskan masalah yang ada diantaranya adalah brainstorming dan identifimasi masalah, perumusan masalah dan penetapan tujuan penetelitan, studi literatur, dan studi lapangan.

\section{B. Pengumpulan Data}

Pada tahap pengumpulan data dilakukan dengan mengumpulkan dua jenis data yaitu data primer dan data sekunder. Data primer didapatkan dengan melakukan pengambilan data langsung dengan sumber seperti wawancara dan pengisian kuisioner oleh objek amatan. Sedangkan disisi lain data sekunder didapatkan menggunakan metode tidak langsung atau melalui perantara lainnya seperti media, literatur, dan lain-lain.

\section{Pengolahan Data}

Pada tahap pengolahan data terdapat beberapa aspek yang akan dibahas antara lain adalah identifikasi job analysis, identifikasi knowledge pegawai, pembuatan river diagram antar pegawai, dan pembuatan stairs diagram antar pegawai.

\section{Analisis dan Interpretasi Data}

Pada tahap analisis dan interpretasi data, dilakukan analisis dan interpretasi data terhadap hasil pengolahan data yang ada yang ada pada bagian sebelumnya. Pada tahap analisis dan interpretasi data ini akan dilakukan empat analisis dan interpretasi. Empat hal tersebut akan membahas mengenai analisis job analysis, analisis identifikasi knowledge pada karyawan, analisis pembuatan river diagram, dan analisis pembuatan stairs diagram.

\section{E. Kesimpulan dan Saran}

Pada tahap ini akan dibahas mengenai kesimpulan dan saran yang diberikan oleh peneliti akan hasil dari penelitian ini. kesimpulan yang akan dihasilkan pada penelitian ini merupakan jawaban dari tujuan penelitian yang telah ditetapkan pada awal penelitian. Dan saran penelitian merupakan rekomendasi yang peneliti berikan bagi perusahaan terkait untuk pengembangan perusahaan setelahnya dan juga rekomendasi bagi penelitian selanjutnya yang ingin melakukan penelitian dengan tema ataupun objek amatan yang sama.

\section{PENGUMPULAN DAN PENGOLAHAN DATA}

\section{A. Profil Perusahaan dan Direktorat}

PT Pelabuhan Indonesia III (Persero) atau lebih dikenal dengan Pelindo III merupakan salah satu Badan Usaha Milik Negara (BUMN) yang bergerak dalam jasa layanan operator terminal pelabuhan. Sebagai operator terminal pelabuhan, perusahaann Pelindo III mengelola 43 pelabuhan dengan 16 kantor cabang yang tersebar di tujuh provinsi di Indonesia meliputi Jawa Tengah, Jawa Timur, Bali, Nusa Tengggara Barat, Nusa Tenggara Timur, Kalmantan Tengah, dan Kalimantan Selatan [1]. Sebagai salah satu BUMN terbesar yang ada di Indonesia yang memiliki peningkatan nilai aset setiap tahunnya, PT Pelindo III (Persero) memiliki visi dan misi sebagai acuan dan tujuan dasar dari berjalannya roda bisnis perusahaan. Adapun visi dan misi dari perusahaan adalah sebagai berikut. 


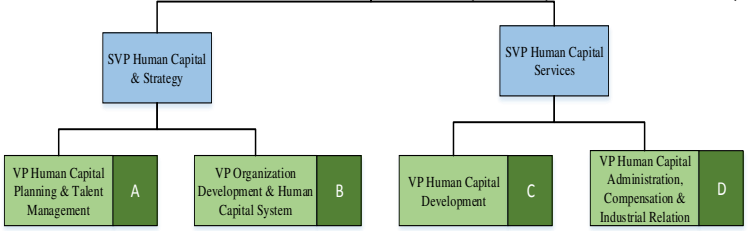

Gambar 1. Organigram Direktorat Human Resource Development.

Visi :

Berkomitmen memacu integrasi logistik dengan layanan jasa pelabuhan yang prima

Misi :

1. Menjamin penyediaan jasa pelayanan prima melampaui standar yang berlaku secara konsisten

2. Memacu kesinambungan daya saing industri nasional melalui biaya logistik yang kompetitif

3. Memenuhi harapan semua stakeholder melalui prinsip kesetaraan dan tata kelola perusahaan yang baik.

4. Menjadikan SDM yang berkompeten, berkinerja handal, dan berpekerti luhur.

5. Mendukung perolehan devisa negara dengan memperlancar arus perdagangan.

Adapun pada penelitian kali ini objek yang akan diteliti adalah direktorat human resource development. Pada direktorat human resource development terdapat dua sub direktorat yaitu subdirektorat human capital and strategy dan subdirektorat human capital services. Kedua subdirektorat tersebut bertanggung jawab kepada masing-masing dua divisi yang akan diukur pada penelitian kali ini.

Pada pengukuran dilakukan kepada masing-masing pegawai pada tiap divisi, pada divisi human capital planning and talent management terdapat 7 pegawai, pada divisi organization and human capital system terdapat 4 pegawai, pada divisi human capital development terdapat 6 pegawai, dan pada divisi human capital administration, compensation, and industrial relation terdapat 11 pegawai.

\section{B. Identifikasi Job Analysis}

Pada proses identifikasi job analysis dilakukan proses pengidentifikasian analisis pekerjaan pada tiap jabatan pada direktorat human resource development. Berdasarkan hasil identifikasi job analysis, divisi human capital planning and talent management memiliki tiga tugas pokok dan fungsi utama yaitu adalah sebagai berikut.

1) Perencanaan pemetaan kompetensi tiap pegawai pada perusahaan

2) Melakukan pemetaan kompetensi tiap pegawai pada perusahaan

3) Melakukan maintenance dari kompetensi tiap pegawai pada perusahaan.

Adapun pada divisi organization development and human capital system memiliki tiga tugas pokok dan fungsi utama antara lain adalah sebagai berikut.
1) Menyediakan berbagai peraturan direksi yang berkaitan dengan perusahaan.

2) Melakukan penyusunan struktur organiasi (STO) pada perusahaan.

3) Melakukan pengukuran beban kerja para pegawai pada perusahaan.

Selain itu pada divisi human capital development terdapat tga tugas pokok dan fungsi utama antara lain adalah sebagai berikut.

1) Menjalankan dan mengadakan pelatihan yang bersifat inhouse

2) Menjalankan dan mengadakan pelatihan yang bersifat exhouse

3) Mengoordinasikan proses kerja praktik yang ditujukan bagi pelajar

Dilain sisi pada divisi human capital administration, compensation, and industrial relation terdapat tiga tugas pokok dan fungsi utama yaitu adalah sebagai berikut.

1) Melaksanakan penertiban terkait disiplin pegawai

2) Melaksanakan penertiban terkait pensiun dini pegawai

3) Memastikan berjalannya laporan harta kekayaan penyelenggara negara (LHKPN)

\section{Identifikasi Knowledge}

Identifikasi knowledge merupakan proses untuk mengidentifikasi pengetahuan-pengetahuan yang terkandung dalam suatu tugas pokok dan tanggung jawab yang secara umum dimiliki oleh pegawai yang bersangkutan. Secara umum identifikasi knowledge dilakukan didahulukan dengan proses knowledge audit. Berdasarkan hasil dari knowledge audit tersebut didapatkan bahwa pada divisi human capital planning and talent management didapat 13 knowledge yang terkandung dari tiga tugas pokok dan fungsi utama, divisi organization development and human capital system memiliki 14 knowledge, divisi human capital development memiliki 19 knowledge, dan pada divisi human capital administration, compensation, and industrial relation memiliki 30 knowledge.

Setelah didapatkan knowledge yang terkandung pada tiap tugas pokok dan fungsi utama pada suatu divisi dilakukan pengidentifikasian knowledge berdasarkan know-how, knowwho, dan know-what. Pengidentifikasian ini dilakukan agar didapatkan beberapa informasi knowledge secara detail diantaranya adalah know-how yaitu untuk kejelasan bagaimana suatu knowledge dapat beflangsung, know-who siapa yang memiliki dan Lexeraspen pedalamankpberkangsungan knowledge

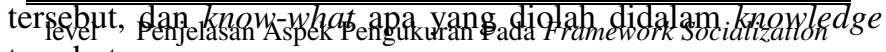
tersebut. Pegawai memiliki kesadaran bahwa berbagi kepada orang

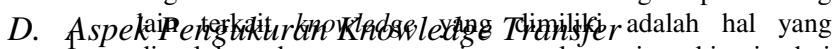
diperlukan dan sangat penting untuk menjaga kinerja dari

Denganm.menggunakan framework SECI (socialization, externalization, combination, internalitzation) yang diterapkan

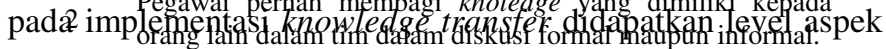
pengukuran yang berdasarkan pada tiap-tiap aspek pada

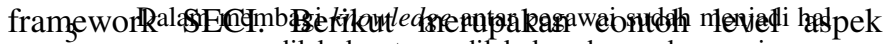

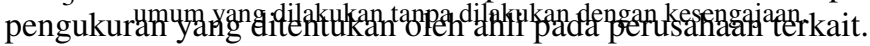

Pegawai memberikan penjelasan kepada orang lain akan

4 pentingnya membagi knowledge dan memberikan contoh praktik yang nyata.

Pegawai memiliki inisiatif untuk mencari inovasi dalam

5 metode sharing knowledge yang paling optimal dalam pekerjaannya sehari-hari. 


\section{E. Pembuatan River Diagram}

Setelah didapatkan aspek pengukuran dilakukan pengukuran terhadap tiap pegawai yang berdasarkan pada target yang telah ditentukan oleh penanggung jawab jabatan tersebut dan pencapaian saat ini (current) yang dicapai oleh pegawai. Berikut merupakan contoh dari perhitungan dari pencapaian.

Tabel 2.

Contoh Perhitungan Pengukuran Input River Diagram

\begin{tabular}{|c|c|c|c|c|c|c|c|}
\hline \multirow{2}{*}{ Kode Knowledge } & \multicolumn{2}{|c|}{ Staf 1} & \multicolumn{2}{|c|}{ Staf 2} & \multirow{2}{*}{ Low } & \multirow{2}{*}{ High } & \multirow{2}{*}{ Gap } \\
\hline & $\mathrm{C}$ & $\mathrm{T}$ & $\mathrm{C}$ & $\mathrm{T}$ & & & \\
\hline KA-1 & 4 & 5 & 1 & 5 & 1 & 4 & 3 \\
\hline KA-2 & 3 & 5 & 2 & 5 & 2 & 3 & 1 \\
\hline $\mathrm{KA}-3$ & 1 & 3 & 1 & 3 & 1 & 1 & 0 \\
\hline $\mathrm{KA}-4$ & 5 & 5 & 2 & 5 & 2 & 5 & 3 \\
\hline KA-5 & 2 & 5 & 1 & 5 & 1 & 2 & 1 \\
\hline KA-6 & 1 & 5 & 1 & 5 & 1 & 1 & 0 \\
\hline $\mathrm{KA}-7$ & 2 & 5 & 1 & 5 & 1 & 2 & 1 \\
\hline KA-8 & 1 & 5 & 1 & 5 & 1 & 1 & 0 \\
\hline
\end{tabular}

Setelah dilakukan pengukuran dilakukan pembuatan river diagram terhadap tiap pegawai. Berikut akan dipaparkan contoh pembuatan river diagram pegawai pada divisi human capital planning and talent management yang memiliki 13 knowledge yang didefinisikan dengan kode knowledge KA. Pengukuran tersebut merupakan pengukuran pegawai pertama pada aspek socialization yang ada pada pekerjaannya.

Garis hijau merupakan garis yang menunjukan pencapaian implementasi pegawai pertama pada divisi human capital planning and talent management, garis merah merupakan garis yang menunjukan target pencapaian yang telah ditentukan oleh penanggung jawab dari pegawia tersebut, dan bagian biru merupakan gap ketercapaian implementasi yang ada pada divisi yang sedang dilakukan pengukuran tersebut.

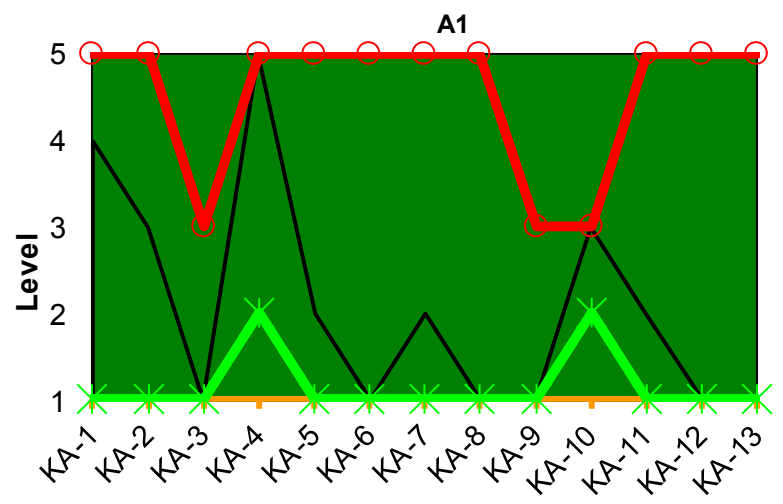

Gambar 2. River Diagram Pegawai.

\section{F. Pembuatan Stairs Diagram}

Stairs diagram dibentuk berdasarkan pada pencapaian level aspek yang telah dicapai oleh pegawai dibandingkan dengan target yang telah ditentukan sebelumnya oleh jabatan atau pihak yang bertanggung jawab atas pegawai tersebut. Berikut merupakan contoh dari pembuatan stairs diagram

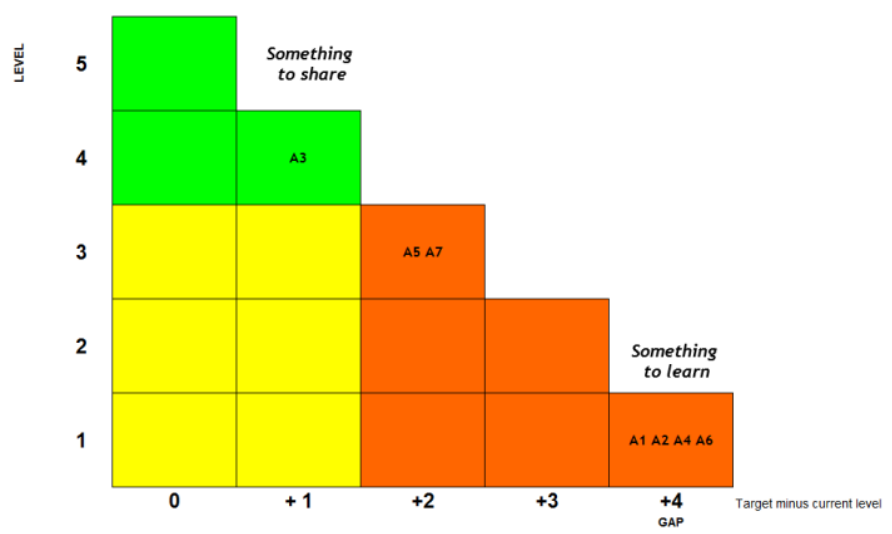

Gambar 3. Stairs Diagram Tiap Knowledge.

Dari contoh stairs diagram diatas dapat diketahui bahwa pegawai yang berada pada zona hijau dapat melakukan knowledge sharing kepada pegawai zona jingga untuk dapat memaksimalkan knowledge yang dilakukan pembuatan stairs diagram tersebut.

\section{HASIL DAN KESIMPULAN}

Dengan dilakukannya penelitian ini didapatkan bahwa terdapat 76 knowledge yang ada pada direktorat human resource development yang diturunkan dari tugas pokok dan fungsi utama dari tiap-tiap divisi yang memiliki jumlah pegawai yang berbeda-beda. Dari 76 knowledge yang didapatkan bahwa keseluruhan dari knowledge yang ada perlu dilakukan evaluasi terhadap berjalannya proses knowledge transfer yang ada pada perusahaan. hal ini dikarenakan sebagian besar dari knowledge-knowledge yang ada masih memiliki gap ketercapaian implementasi knowledge transfer yang besar antara pegawai satu dan yang lainnya.

Selain itu dilain sisi dapat dilihat bahwa masih belum semua pegawai mencapai target-target ketercapaian yang telah ditentukan sebelumnya. Dan juga masih ditemukan mayoritas ketercapaian implementasi knowledge transfer pada tiap-tiap knowledge masih belum mencapai nilai target yang ada. Hal ini menggambarkan bahwa secara umum ketercapaian imlpementasi knowledge transfer pada objek tidak berjalan dengan baik. Hal ini dapat menjadi perhatian khusus bagi perusahaan untuk dapat melakukan perbaikan-perbaikan untuk menjaga proses knowledge transfer demi keberlangsungan knowledge management yang dilakukan oleh objek penelitian.

\section{DAFTAR PUSTAKA}

[1] Pelindo III, "Sekilas Pelindo III," 2015. [Online]. Available: https://www.pelindo.co.id/profil-perusahaan/tentang-kami/sekilaspelindo-iii .

[2] N. Sadnyana, "Knowledge Management Pada PT. Pelindo III (Persero) [Wawancara]." 2017.

[3] "Strategic Management Journal," in Making Knowledge The Bais Of A Dynamic Theory Of The Firm, pp. 45-62.

[4] E. M. Awad and H. Ghaziri, "Knowledge Management," Knowl. Manag., p. 249, 2004. 
[5] R. S. Kaplan and D. Norton, The Balanced Scorecard: Translating Strategy Into Action. Boston: Harvard Business School Press, 1996.

[6] C. Hubert and D. Lemons, "APQC's Levels Of Knowledge
Management Maturity," Achiev. KM Matur. Bus. Impact, p. 5, 2017. 